\title{
O PAPEL DO CONSELHO DE SEGURANÇA DA ONU NO TRIBUNAL PENAL INTERNACIONAL
}

Isteissi Aires Garcia Somenzari ${ }^{1}$

\section{RESUMO}

O Estatuto de Roma atribuiu um papel significativo ao Conselho de Segurança da ONU dentro da jurisdição do Tribunal Penal Internacional. Com o final da Segunda Guerra Mundial este Conselho ganhou relevância no cenário mundial, o que em parte explicaria sua competência para enviar casos ao Tribunal ou interromper investigações. No entanto, por ser um órgão de grande força política, questiona-se a legitimidade dessa interferência e, embora se defenda que esse poderá ser um fator de ampliação da competência do Tribunal, teme-se que ela seja usada discricionariamente pelos países com poder de veto, de forma que seus interesses prevaleçam frente aos Direitos Humanos.

\section{ABSTRACT}

The Statute of Rome assigned an important role to the Security Council of the United Nations inside the International Criminal Court jurisdiction. After the end of the II World War this Council got a great relevance worldwide, what could explain its competence to send cases to the ICC or to cease investigations. However, because it's an organism with a large political power, people question the legitimacy of this influence and, although it is defended that it could be a factor of enlarging the competence of the Court, it is feared would be used discretionaryly by the countries enfranchised with the veto power to make their interests prevail over to the Human Rights.

\footnotetext{
${ }^{1}$ Acadêmica de Direito da Universidade Federal do Paraná
}

Revista Brasileira de Direito Internacional, Curitiba, v.1, n.1, jan./jun.2005 
Palavras Chave: TRIBUNAL PENAL INTERNACIONAL; CONSELHO DE SEGURANÇA DA ONU

Keywords: INTERNATIONAL CRIMINAL COURT - SECURITY COUNCIL OF THE UN

\section{INTRODUÇÃO}

Os conflitos entre cidadãos de diferentes nacionalidades e até mesmo entre Estados existem desde a antiguidade. Entretanto, com as novas tecnologias, as armas provocam estragos cada vez maiores, aumentando o número de vítimas e provocando danos irreparáveis. Há muito tempo a comunidade internacional vem pensando em uma maneira para reprimir e punir os responsáveis por crimes internacionais, principalmente os crimes contra a humanidade.

Foram várias as tentativas para punir criminosos de guerra e os responsáveis por crimes contra a humanidade. O Tribunal de Nuremberg, por exemplo, foi criado para julgar os responsáveis pelos crimes ocorridos no Terceiro Reich. No entanto, sempre havia a sombra da parcialidade, já que, no caso de Nuremberg, foi um Tribunal dos Aliados.

$\mathrm{Na}$ Conferência de Roma foi criado o Tribunal Penal Internacional, com o objetivo de ser um tribunal para vencedores e vencidos. No entanto, alguns pontos ainda causam polêmica e deixam margem a críticas com relação a sua imparcialidade. Um desses pontos é o papel do Conselho de Segurança no Tribunal.

Por esse motivo, é necessário abordar algumas características do Tribunal Penal Internacional, bem como do Conselho de Segurança da ONU, para abrir possibilidades de questionamento sobre a relação entre esses dois organismos internacionais.

Para isso, neste artigo, optou-se por resgatar, primeiramente, aspectos relevantes do Conselho de Segurança da ONU, desde os objetivos de sua criação até as polêmicas propostas para sua ampliação, para então abordar o 
Tribunal Penal Internacional, com suas peculiaridades e inovações em face de outros tribunais internacionais.

A partir dessa análise será possível fazer uma comparação entre os objetivos de ambos e refletir sobre a influência, jurídica e política, que o Conselho de Segurança tem sobre a Corte e as conseqüências dessa intervenção, para depois analisar o caso de Darfur, no Sudão, no qual a interferência do CS possibilitou a ampliação da jurisdição do TPI para abranger o conflito no Estado.

Revista Brasileira de Direito Internacional, Curitiba, v.1, n.1, jan./jun.2005 


\section{O CONSELHO DE SEGURANÇA DA ONU}

A manutenção da paz e segurança internacionais, função descrita no artigo 24 da Carta da Organização das Nações Unidas, constitui o principal objetivo do Conselho de Segurança da ONU. Este Conselho, juntamente com a Assembléia Geral, constituem os principais órgãos da Organização das Nações Unidas, criada em $1945 \mathrm{com}$ a finalidade de instituir e manter a paz entre os Estados, buscando a cooperação e o desenvolvimento econômico, social e cultural de seus membros, reprimir atos de agressão e, principalmente, promover e estimular o respeito aos direitos humanos.

A criação da ONU, após a Segunda Guerra Mundial, na Conferência de São Francisco, foi a concretização de uma antiga idéia de estabelecer uma paz durável. De acordo com Celso D. de Albuquerque Mello, foi a primeira vez na história que houve a "concreta institucionalização de uma idéia de governo mundial”2.

A Assembléia Geral é um órgão político não-permanente. Seus membros reúnem-se uma vez por ano e cada Estado-membro tem direito a um voto. Suas funções estão descritas na Carta de São Francisco no Capítulo IV. Convém ressaltar que esse é o órgão responsável por eleger os membros não permanentes do $\mathrm{CS}^{3}$.

Ao contrário da Assembléia Geral, o Conselho de Segurança é um órgão permanente. Por ser, na prática, o principal órgão das Nações Unidas, responsável pela manutenção da paz e da segurança internacionais, suas decisões devem ser cumpridas pela ONU, ao contrário dos outros órgão que fazem apenas recomendações. Para que suas decisões sejam cumpridas ele pode, inclusive, utilizar medidas drásticas como o uso da força armada. Sua principal finalidade, descrita no artigo 24 da Carta, gera inúmeras interpretações para atuações do CS, proporcionando, principalmente para os membros permanentes, um poder muitas vezes até discricionário, devido a generalidade e amplitude dos termos.

\footnotetext{
${ }^{2}$ MELLO, Celso D. de Albuquerque. Curso de Direito Internacional Público. 11. ed. Rio de Janeiro: Renovar, 1997, p. 590.

${ }^{3}$ Neste trabalho a sigla CS será utilizada como abreviação de "Conselho de Segurança".
}

Revista Brasileira de Direito Internacional, Curitiba, v.1, n.1, jan./jun.2005 
Ele é composto por 15 membros: cinco permanentes e dez não permanentes. Os membros permanentes são aqueles que "fundaram" a Organização, países que durante a Segunda Guerra Mundial lutaram contra o Eixo: os Estados Unidos da América, a União das Repúblicas Socialistas Soviéticas (que depois foi substituída pela Rússia), a República da China, o Reino Unido. A França juntou-se aos aliados na Conferência de São Francisco e ganhou uma cadeira permanente no Conselho.

Os outros dez membros não-permanentes são eleitos pela Assembléia Geral pelo período de dois anos e, de acordo com a Carta das Nações Unidas, devem atender a uma distribuição geográfica, sendo cinco países afroasiáticos, dois da América Latina, um do leste europeu e dois da Europa Ocidental e outros Estados remanescentes.

Entre as funções do Conselho de Segurança pode-se destacar a regulamentação de armamentos, contida no artigo 26 da Carta de São Francisco, o dever de agir nos casos de ameaça a paz e de agressão e o dever de tomar medidas para o cumprimento das sentenças da Corte Internacional de Justiça, órgão jurídico internacional com competência para julgar conflitos entre Estados.

Outra função do Conselho de Segurança é a criação de tribunais $a d$ hoc. Esta não é uma função contida expressamente na Carta, mas está implícita. Resulta da interpretação do artigo 29 da Carta de São Francisco. ${ }^{4}$

A questão referente ao $C S$ responsável pelo maior número de críticas a esse órgão diz respeito ao sistema de votação. A Carta da Organização diz que nas questões processuais as decisões do Conselho devem ser tomadas por voto afirmativo de nove membros; nos outros assuntos, pelo voto afirmativo de nove membros, inclusive os votos de todos os membros permanentes (artigo 27). Nesse último caso surge a figura do poder de veto que, embora não seja explicita, manifesta-se em várias ocasiões, pois, para que uma decisão seja tomada, todos os membros permanentes devem entrar em um consenso, seguindo o princípio da unanimidade. Esse tipo de situação classifica os países em diferentes níveis, o que não poderia acontecer, já que a Organização, na 
época de sua criação, pretendia representar uma vitória da democracia sobre o totalitarismo.

Como a Carta não define quais são as questões processuais, estabelecer essa definição fica a critério do próprio Conselho. Dessa forma, um poder instituído para ser usado apenas quando fosse de máxima importância, restrito às questões de segurança, acabou sendo usado indiscriminadamente, provocando em alguns casos, principalmente durante a Guerra Fria, praticamente a paralisação da ONU.

Embora no Estatuto, no artigo 2, parágrafo 1, fique estabelecido que "a Organização é baseada no princípio da igualdade de todos os seus membros", a figura do veto estabelece duas categorias de Estados-membros. Essa questão configura uma contradição em uma organização que pretende ser democrática.

Além disso, não há nenhum controle juridicamente institucionalizado sobre o Conselho. Embora países como a França, a Bélgica e a Holanda defendam a idéia desse controle jurídico, a maioria dos países alega que se ele fosse submetido a qualquer forma de fiscalização, inclusive a da Corte Internacional de Justiça, o Conselho ficaria enfraquecido e teria sua atuação prejudicada. Como não há qualquer interferência, nem controle de legalidade, o CS aplica um Direito criado por ele mesmo. Diz-se inclusive que "os poderes do CS são tão discricionários que não é criado um estado de direito, mas um estado policial". ${ }^{5}$ A posição de Kelsen defende a superioridade absoluta do CS, sendo possível até que ele aprovasse uma resolução em desconformidade com o Direito Internacional se fosse necessária para cumprir suas funções. ${ }^{6}$

Essas, entre outras contradições existentes na Carta, podem ser reflexo das demoradas e difíceis negociações que a originaram, mas são alguns dos motivos para que hoje se discuta a reforma da $\mathrm{ONU}$, prometida pelo seu atual Secretário Geral Kofi Annan, e um possível alargamento do Conselho

\footnotetext{
${ }^{4}$ Carta de São Francisco, artigo 29: "O Conselho de Segurança poderá estabelecer órgãos subsidiários que julgar necessários para o desempenho de suas funções".

${ }^{5}$ MELLO, Celso D. de Albuquerque. Curso de Direito Internacional Público. 11. ed. Rio de Janeiro: Renovar, 1997, p. 594

${ }^{6}$ MELLO, Celso D. de Albuquerque. Curso de Direito Internacional Público. 11. ed. Rio de Janeiro: Renovar, 1997, p. 594
}

Revista Brasileira de Direito Internacional, Curitiba, v.1, n.1, jan./jun.2005 
de Segurança. Defendendo essa reforma, alguns países argumentam que hoje a ONU conta com 191 membros $^{7}$, não apenas com os 51 países que assinaram a Carta na data de sua promulgação.

Os países que sugerem uma ampliação do Conselho têm como principal objeto o poder do veto e, atualmente, existem três propostas para a modificação desse órgão: o projeto africano, o projeto do G4 e outro que reúne vários países.

O projeto proposto por países africanos sugere que as cadeiras nãopermanentes do Conselho passem de 10 para 20 e as permanentes de 5 para 11, possuindo estes, desde logo, o poder de veto. Outro projeto é o chamado "União para o Consenso", formado pela Argentina, Paquistão e Itália, entre outros. Tais países são contra qualquer mudança no Conselho de Segurança, pois alegam que isso aumentaria as diferenças entre seus membros e causaria desavenças regionais; sugerem apenas que sejam criadas mais dez vagas para membros não-permanentes.

Há ainda a proposta do G4, composto por Brasil, Alemanha, Japão e Índia, que defende $\mathrm{o}$ ingresso dos quatro como membros permanentes do Conselho de Segurança. No último documento entregue pelo grupo, os países abriram mão do poder de veto pelo período de quinze anos, na intenção de conquistar a simpatia dos cinco membros permanentes, principalmente dos Estados Unidos. Depois dessa mudança no projeto original, a França demonstrou apoio à proposta.

Uma necessária atualização da ONU, já que desde que foi criada, há 60 anos, não passa por modificações, e a necessidade de legitimar a Organização, constituindo um Conselho não apenas de vencedores, são argumentos que tentam justificar a reforma. Por outro lado, deve-se questionar se o aumento dos membros permanentes não implicaria na paralisação do órgão, tornando-o menos eficaz. Também é necessário ressaltar que os países com cadeiras permanentes são os que possuem maior poder de intervenção. Talvez o Estado integre o CS porque detém mais poder, e não o contrário. ${ }^{8}$

\footnotetext{
${ }^{7}$ Informação disponível em <www.onu-brasil.org.br>, acesso em 31/10/2005.

8 SEITENFUS, Ricardo. Palestra proferida no $3^{\circ}$ Congresso de Direito Internacional, que ocorreu de 24 a 27 de agosto de 2005, em Curitiba.
}

Revista Brasileira de Direito Internacional, Curitiba, v.1, n.1, jan./jun.2005 
Além disso, não se pode fazer qualquer modificação na Carta de São Francisco sem o consentimento dos membros do Conselho de Segurança, sendo, mais uma vez, o poder de veto um obstáculo. Há, ainda, uma questão política, pois a mudança dos membros permanentes seria como um "esquecimento" da $2^{\text {a }}$ Guerra Mundial, já que os membros permanentes são os vencedores dessa guerra. Permitir que outros países ocupem esse lugar seria como deixar de lado a posição conquistada no pós guerra, o que iria contra a verdadeira intenção desses países quando foi criada a Organização: permitir acesso restrito às instâncias decisórias somente a um pequeno e seleto grupo de países ${ }^{9}$.

Antes de tratar da relação entre o Conselho de Segurança da ONU e o Tribunal Penal Internacional, faz-se necessário observar alguns aspectos do Tribunal, assim como seus objetivos e funcionamento.

${ }^{9}$ SEITENFUS, Ricardo. Manual das Organizações Internacionais. Porto Alegre: Livraria do Revista Brasileira de Direito Internacional, Curitiba, v.1, n.1, jan./jun.2005 


\section{O TRIBUNAL PENAL INTERNACIONAL}

Em julho de 2002 têm início as atividades do Tribunal Penal Internacional, reafirmando os princípios e objetivos contidos na Carta das Nações Unidas e com o dever de se abster de atuar de forma incompatível com os objetivos da ONU.

Esse Tribunal surge no cenário internacional como resultado de um processo de discussões ocorrido principalmente na Conferência de Roma e como a concretização do desejo de uma jurisdição internacional permanente com competência para os mais graves crimes contra a humanidade e os direitos humanos. Criou-se, então um Tribunal não apenas de Direitos Humanos, mas que também abrange os Direitos Humanitários ${ }^{10}$.

Inicialmente pensou-se na criação desse Tribunal através de uma resolução do Conselho de Segurança da ONU. Uma das razões para o abandono dessa idéia foi o fato de que esse Conselho não possui a faculdade de adotar regras gerais e impessoais; ele não é um legislador internacional ${ }^{11}$. Além disso, a instituição de um tribunal através de um tratado multilateral proporciona uma valorização mais aprofundada e detalhada da sua criação. Também possibilita a participação de um maior número de Estados nas discussões, contribuindo para a formação de um tribunal mais justo e diversificado, abrangendo características jurídicas e juristas de diversos

\footnotetext{
Advogado, 1997, p. 108.

${ }_{10}$ Deve-se destacar que existem diferenças entre Direitos Humanos e Direitos Humanitários. Segundo GUIDO SOARES, "os direitos humanos foram concebidos tendo em vista uma situação de paz, quer dizer, de normalidade interna, em que o estado poderia estabelecer e realizar seus fins, sem excepcional influência de fenômenos externos ou interveniência de outros Estados, portanto, tendo por campo de atuação o próprio ordenamento jurídico nacional, naqueles casos em que os indivíduos colocavam-se em face do Estado sob cujo ordenamento encontravam-se submetidos, seja por força de sua nacionalidade, seja pelo fato de nele estarem fisicamente localizados. Já os outros três [direitos dos refugiados, direito humanitário e normas que regem o instituto do asilo] nasceram para regular situações em princípio anormais, como as situações de grave comoção interna nos Estados ou de guerra, situações essas em que os ordenamentos jurídicos nacionais encontram-se em perigo de desagregação (por vezes com as normas constitucionais suspensas) e nas quais houve necessidade desregulamentar os direitos de pessoas que buscam refúgio ou asilo em outros Estados, ou, ainda, daquelas pessoas deslocadas por efeito das operações militares e, enfim, para conseguir tratamento menos cruel às populações civis e aos próprios combatentes". SOARES, Guido Fernando Silva. Curso de Direito Internacional Público, v. 1. São Paulo: Atlas, 2002. p. 335-336.
}

Revista Brasileira de Direito Internacional, Curitiba, v.1, n.1, jan./jun.2005 
sistemas jurídicos, e não apenas dos sistemas utilizados pelos países que constituem o CS, o que poderia tornar o tribunal bastante limitado.

Outra razão é a consagração dos tratados multilaterais na criação de tribunais internacionais. É o método mais utilizado para a formação de tribunais permanentes, como é o caso do Tribunal do Mar, criado pela Convenção das Nações Unidas sobre Direito do Mar de 1982, e da Corte Interamericana de Direitos Humanos, criada pela Convenção Americana de Direitos Humanos, em 1969.

Antes do TPI, o mais comum para o julgamento desses crimes era a criação de tribunais de exceção pelo Conselho de Segurança da ONU, como aconteceu em Ruanda e na ex-lugoslávia, ou tratados para a criação de tribunais para casos específicos, como o Tratado de Londres, que criou o Tribunal de Nuremberg.

Segundo Sylvia Steiner, esses "tribunais ad hoc, que, se cumpriram e estão cumprindo papel relevante na evolução dos sistemas internacionais de proteção aos direitos fundamentais, poderiam ser vistos com restrições, na medida em que assemelhados a tribunais de exceção, criados para processo e julgamento de fatos ocorridos antes ou durante sua instalação". ${ }^{12} \mathrm{O}$ fato de a criação desses tribunais não ter respeitado alguns princípios do Direito, como o Princípio da Legalidade e do Juiz Natural, até hoje eles são bastante criticados.

Daí a necessidade de uma Corte permanente e imparcial, que não seja estabelecida por Estados vencedores, como foi o Tribunal de Nuremberg, não vulnerável às manipulações políticas e com competência para julgar os sujeitos sem distinções hierárquicas ou imunidades para as autoridades, pois como ressalta Hannah Arendt, "os Tribunais Internacionais Militares eram internacionais só no nome, sendo de fato cortes dos vitoriosos". ${ }^{13}$

\footnotetext{
${ }^{11}$ SENNI, Tommaso. II Tribunale Penale Internazionale: il problema del ruolo del Consiglio di sicurezza della Nazioni Unite. Disponível em: <www.rivistagiuridica.it/articoli/ig_dot_16042002_01.htm>. Acesso em: 20/12/2005.

${ }^{12}$ STEINER, Sylvia. O perfil do juiz do Tribunal Penal Internacional. In: CHOUKR, Fauzi Hassan. AMBOS, Kai. Tribunal Penal Internacional. São Paulo: Revista dos Tribunais, 2000. p. 293

${ }^{13}$ ARENDT, Hannah. Eichmann em Jerusalém. Um relato sobre a banalidade do mal. Tradução de José Rubens Siqueira. São Paulo: Companhia das Letras, 1999. p. 278.
}

Revista Brasileira de Direito Internacional, Curitiba, v.1, n.1, jan./jun.2005 
Além disso, a Corte tem fundamento em alguns princípios de Direito Penal que não foram observados em outros tribunais devido à imprevisibilidade de crimes tão graves, como foram os crimes nazistas. Entre esses princípios são destacados os princípios "nulla poena sine lege", que estabelece que a pessoa só poderá ser punida em conformidade com as disposições do Estatuto, e o da "não retroatividade ratione personae", pelo qual uma pessoa só será considerada criminalmente responsável por conduta posterior a entrada em vigor do Estatuto e, em caso de mudança no direito durante o julgamento, será aplicado o mais favorável ao réu.

Outra inovação deste tribunal é o fato de as funções do acusador e do julgador estarem separadas em órgãos diferentes. A primeira cabe ao Procurador, que atuará de forma independente e será o responsável por examinar e investigar as informações devidamente fundamentadas sobre os crimes de competência do Tribunal.

A tarefa de julgar é de responsabilidade dos juízes e está dividida em três órgãos principais: Câmara de Julgamento Preliminar, Câmara de Primeira Instância e Câmara de Apelações.

Existem três Câmaras de Julgamento Preliminar, ou Pre-Trial Chamber, cada uma composta por três juízes. Essas câmaras analisam se 0 caso preenche todos os requisitos para ser admitido na Corte. Só então ele será realmente julgado pela Câmara de Primeira Instância, ou Trial Division e, em caso de recurso, remetido a Câmara de Apelações, ou Appeals Division. O Tribunal é composto por 18 juízes ao todo, sendo que há mobilidade entre eles, podendo um mesmo juiz participar em mais de uma das Câmaras. $O$ magistrado também está autorizado, nos limites do Estatuto e sem interferir na atuação do Procurador, a buscar provas sobre o caso que esteja julgando.

Sua jurisdição poderá ser exercida em dois casos: quando o acusado de ter cometido um crime for nacional de um Estado-Parte ou se a conduta for cometida no território de um Estado-Parte. Considera-se sob a jurisdição do TPI também a conduta cometida a bordo de um navio ou aeronave com matrícula em um Estado Parte, conforme artigo 12 do Estatuto de Roma. 
A investigação pode ser iniciada pelo Procurador, como já foi dito. Entretanto, também poderá ser iniciada se este receber uma denúncia de indícios da prática de crimes de competência do Tribunal de um Estado-Parte ou se receber essa denúncia do Conselho de Segurança, conforme o artigo 13 do Estatuto de Roma.

Uma investigação, depois de iniciada, poderá ser paralisada se solicitada pelo Conselho de Segurança. Esse adiamento do inquérito pode ser feito por um período de 12 meses a contar da data em que o Conselho o solicitar através de uma resolução aprovada conforme o disposto no Capítulo VII da Carta da ONU. Esse pedido ainda poderá ser renovado sob as mesmas condições.

Devido principalmente a essas duas atribuições feitas pelo Estatuto de Roma ao Conselho de Segurança, torna-se necessária uma análise mais detalhada das conseqüências que elas acarretam à jurisdição do TPI, suas vantagens e desvantagens para os Estados membros e para a comunidade internacional.

Revista Brasileira de Direito Internacional, Curitiba, v.1, n.1, jan./jun.2005 


\section{A RELAÇÃo ENTRE O CONSELHO DE SEGURANÇA E O TPI}

A Corte tem sua competência fortemente relacionada à do Conselho de Segurança. Pode-se dizer que sua competência engloba a do Conselho na medida em que se propõe a proteger a justiça internacional, a principal responsabilidade desse órgão da ONU.

Logo no preâmbulo do Estatuto fica estabelecida a finalidade de proteção à justiça internacional, confundindo-se com a principal responsabilidade do CS, abordada pelo Capítulo VII da Carta das Nações Unidas, de manter a paz e a justiça internacionais. Esse é, provavelmente, um dos motivos que justifica a pressão para que fosse concedida uma posição de destaque ao Conselho de Segurança dentro do Estatuto de Roma.

O estreito relacionamento entre o TPI e o CS também é demonstrado com as análises dos artigos 24 da Carta e $5^{\circ}$, I do Estatuto. O primeiro reafirma a competência do Conselho na manutenção da paz e segurança internacionais e delega a este órgão a responsabilidade de agir em nome dos membros das Nações Unidas no cumprimento de seus deveres. O segundo limita a competência de julgar do Tribunal aos crimes mais graves que afetam a comunidade internacional: o genocídio, os crimes contra a humanidade, os crimes de guerra e o crime de agressão. A partir do momento que o Conselho reconheceu as violações de Direitos Humanos como uma ameaça à paz ${ }^{14}$, são justamente esses os principais crimes que ele deve evitar e tentar reprimir utilizando o poder conferido pelos membros da ONU.

Entretanto, conforme afirma Flávia Piovesan e Daniela Ribeiro Ikawa, "a relação entre o Tribunal Penal Internacional e o Conselho de Segurança tem implicações diretas sobre os Estados-Partes no Estatuto, pois altera, num primeiro momento, o grau de igualdade entre esses Estados e, num segundo momento, o grau de imparcialidade da justiça no âmbito internacional” ${ }^{15}$, sendo

\footnotetext{
${ }^{14}$ A Resolução 746 de 1992 sobre o conflito na Somália estabelece: "... the magnitude of the human suffering caused by the conflict and concerned that the continuation of the situation in Somalia constitutes a threat to international peace and security".

${ }_{15}$ PIOVESAN, Flávia. IKAWA, Daniela Ribeiro. O Tribunal Penal Internacional e o Direito Brasileiro. In: FERRAZ, D.A. HAUSER, D.A. A Nova Ordem Mundial e os Conflitos Armados. Belo Horizonte: Mandamentos, p. 212-213.
}

Revista Brasileira de Direito Internacional, Curitiba, v.1, n.1, jan./jun.2005 
que a imparcialidade é um dos principais objetivos do Tribunal. Isso ocorre porque o poder que o Estatuto delega ao CS atribui faculdades distintas das asseguradas a qualquer outro Estado parte do Tribunal. Dessa forma, o Conselho possui um grande peso dentro do Estatuto, o que causa problemas, além de jurídicos, políticos.

Atualmente, o CS é o único órgão da ONU com faculdade de atuar junto ao TPI. No entanto, um primeiro projeto, elaborado em 1951, concedia essa faculdade à Assembléia Geral, com base na sua responsabilidade principal de proteger os Direitos Humanos e secundariamente de cooperar na manutenção da paz e da segurança internacionais, conforme artigos 55 e 11 da Carta de São Francisco.

Segundo Tommaso Senni ${ }^{16}$, não se propunha a concessão desses direitos ao Conselho de Segurança naquela época por causa dos "vetos cruzados", muito comuns durante a Guerra Fria, que apareciam quando os Estados Unidos não aprovavam as decisões da URSS ou vice e versa. Essas divergências políticas impediram a entrada de vários Estados na ONU e acabavam paralisando o Conselho. Nesse contexto, a Assembléia Geral ganhou grande importância e destaque, sendo conferida a ela uma faculdade importante nesse primeiro projeto pela sua eficiência dentro da Organização. Com o fim da Guerra Fria, e com os membros permanentes do Conselho de Segurança melhor integrados, seria lógico que eles buscassem ampliar sua influência e realmente utilizar o seu poder, agindo até mesmo como a "polícia do mundo".

Uma outra característica que Tommaso Senni destaca refere-se ao caráter obrigatório das decisões do Conselho, enquanto a Assembléia Geral faz apenas recomendações aos membros da ONU.

A interferência do Conselho de Segurança na jurisdição do Tribunal Penal Internacional será analisada sob dois aspectos: a autorização concedida ao Conselho de Segurança para fazer denúncias ao promotor de situações em

\footnotetext{
${ }^{16}$ SENNI, Tommaso. II Tribunale Penale Internazionale: il problema del ruolo del Consiglio di sicurezza della Nazioni Unite. Disponível em:

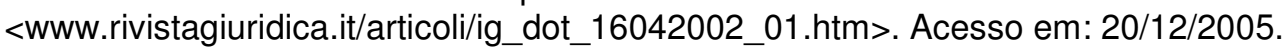

Revista Brasileira de Direito Internacional, Curitiba, v.1, n.1, jan./jun.2005 
que haja indícios de ter ocorrido a prática de um ou mais crimes tipificados no Estatuto; e a possibilidade que o Conselho tem de interromper uma investigação ou procedimento do Tribunal - questões abordadas pelos artigos 13 e 16 respectivamente.

\subsection{O ARTIGO 13 DO ESTATUTO DE ROMA}

O primeiro artigo do Estatuto que delega poder ao Conselho de Segurança, artigo 13, diz:

O Tribunal poderá exercer a sua jurisdição em relação a qualquer um dos crimes a que se refere o artigo $5^{\circ}$, de acordo com o disposto no presente Estatuto, se:

a) Um Estado-Parte denunciar ao Procurador, nos termos do artigo 14, qualquer situação em que haja indícios de ter ocorrido a prática de um ou vários desses crimes;

b) O Conselho de Segurança, agindo nos termos do Capítulo VII da Carta das Nações Unidas, denunciar ao Procurador qualquer situação em que haja indícios de ter ocorrido a prática de um ou vários desses crimes; ou

c) O Procurador tiver dado início a um inquérito sobre tal crime, nos temros do disposto no artigo 15.

Esse artigo torna possível a instauração de uma investigação no TPI para os países que não fazem parte do Estatuto através de uma denúncia do CS. Essa questão pode ser tanto um problema quanto uma ajuda para a jurisdição do Tribunal.

A Índia, por exemplo, que não assinou o Estatuto de Roma, é contra essa prerrogativa do CS. Segundo DELGADO, o país considera que "a presença do CS neste rol implica na aceitação da intromissão de membros do Conselho que não queriam aderir ao TPI, ou seja, ao mesmo tempo que não se submetiam às obrigações decorrentes do Estatuto, possuíam o privilégio de nele intervir"17.

Os Estados Unidos foram contra a criação de um Tribunal Penal Internacional permanente e, apesar de terem assinado o Estatuto de Roma no final do Governo de Bill Clinton, não o ratificaram. No entanto, a delegação americana defendeu a interferência do Conselho de Segurança no Tribunal:

\footnotetext{
${ }^{17}$ DELGADO, José Manuel A. de Pina e TIUJO, Liriam Kiyimi. Tribunais Penais Internacionais. In: BARRAL, Welber (org.). Tribunais Internacionais: mecanismos contemporâneos de solução de controvérsias. Florianópolis: Fundação Boiteux, 2004. p. 78.
}

Revista Brasileira de Direito Internacional, Curitiba, v.1, n.1, jan./jun.2005 
insistiam na necessidade de se respeitar o papel que foi atribuído ao CS em matéria de paz e segurança internacionais ${ }^{18}$. Dessa forma, ficariam imunes à jurisdição do Tribunal e, ao mesmo tempo, teriam influência sobre ele.

Por outro lado, a atuação conjunta de membros do Estatuto de Roma e dos Estados permanentes do CS pode dar maior efetividade as investigações do Tribunal conferindo a ele um caráter universal. Para Flávia Piovesan e Daniela Ribeiro Ikawa, a participação do CS no Tribunal não implica a submissão do TPI, muito pelo contrário, traz vantagens para este e amplia seu alcance, o que pode ser tão importante na concretização de seus objetivos quanto o princípio da igualdade entre os Estados. ${ }^{19}$

Essa questão foi bastante discutida em Roma. Como resultado do debate entre as posições representadas pelas delegações da Índia e dos EUA houve a aprovação do artigo 13 , porém não como queriam os norteamericanos. Eles defendiam que toda e qualquer acusação no TPI deveria passar pela aprovação do Conselho. Para equilibrar, foi concedida a criação do artigo 16, que será analisada no próximo tópico.

\title{
4.2 O ARTIGO 16 DO ESTATUTO DE ROMA
}

O artigo 16 trata do adiamento do inquérito e procedimento criminal, afirmando que:

\begin{abstract}
Nenhum inquérito ou procedimento criminal poderá ter início ou prosseguir os seus termos, com base no presente Estatuto, por um período de doze meses a contar da data em que o Conselho de Segurança assim o tiver solicitado em resolução aprovada nos termos do disposto no Capítulo VII da Carta das Nações Unidas; o pedido poderá ser renovado pelo Conselho nas mesmas condições.
\end{abstract}

De acordo com este artigo o Conselho de Segurança pode interromper inquéritos ou procedimentos criminais no TPI, ou impedir que prossigam,

\footnotetext{
${ }^{18}$ DELGADO, José Manuel A. de Pina e TIUJO, Liriam Kiyimi. Tribunais Penais Internacionais. In: BARRAL, Welber (org.). Tribunais Internacionais: mecanismos contemporâneos de solução de controvérsias. Florianópolis: Fundação Boiteux, 2004. p. 79.

${ }^{19}$ PIOVESAN, Flávia. IKAWA, Daniela Ribeiro. O Tribunal Penal Internacional e o Direito Brasileiro. In: FERRAZ, D.A. HAUSER, D.A. A Nova Ordem Mundial e os Conflitos Armados. Belo Horizonte: Mandamentos, 2002. p. 213.
}

Revista Brasileira de Direito Internacional, Curitiba, v.1, n.1, jan./jun.2005 
através de uma Resolução aprovada nos termos do disposto no Capítulo VII da Carta das Nações Unidas.

Essa questão é responsável por muita preocupação por parte de alguns Estados-Membros, pois pode paralisar a jurisdição da Corte, tornando-a ineficaz, e ainda prejudicar sua imparcialidade. Países membros do CS, principalmente os membros permanentes, podem usar esse dispositivo para evitar um procedimento criminal que atinja seus nacionais, já que as forças armadas desses países freqüentemente participam de missões de paz pela ONU e poderiam ser alvo de investigações no TPI. ${ }^{20}$

No entanto, Flávia Piovesan ressalta que a versão original do Estatuto previa que era vedado ao Tribunal processar um caso que estivesse sendo analisado pelo Conselho de Segurança e que versasse sobre uma ameaça ou um atentado à paz ou sobre um ato de agressão, nos termos do Capítulo VII da Carta da ONU. ${ }^{21}$ Dessa forma, o Tribunal só poderia agir com a permissão do Conselho. A versão final do Estatuto limitou consideravelmente essa influência, o que leva alguns autores a dizer que o Conselho detém um papel bastante reduzido no TPI face as suas responsabilidades asseguradas na Carta de São Francisco.

Além disso, o fato de a atuação do Conselho depender de um consenso entre os cinco membros permanentes pode tornar a atuação do órgão muito difícil, tanto na instauração de investigações como na obstrução de um processo já iniciado. A recusa dos EUA em apoiar o TPI pode levar o país a utilizar seu poder de veto quando se tratar de enviar um caso à Corte.

O motivo dessa falta de apoio não resulta apenas da eventual perda de poder do Estado em relação a situação anterior ao TPI, quando a criação de tribunais penais internacionais dependiam da decisão dos cinco membros permanentes do Conselho, mas demonstra também um receio de que suas

20 A posição brasileira durante as negociações em Roma foi flexível no que diz respeito a presença do Conselho de Segurança no Tribunal. Admitia que o órgão pudesse iniciar um processo, mas era contra a possibilidade de investigações ou processos serem suspensos pelo CS. JARDIM, Tarciso Dal Maso. O Tribunal Penal Internacional e sua importância para os Direitos Humanos. Disponível em: <www.dhnet.org.br/direitos/sip/tpi/dalmaso.htm>. Acesso em: 07/07/2005.

Revista Brasileira de Direito Internacional, Curitiba, v.1, n.1, jan./jun.2005 
tropas em missões internacionais sejam denunciadas pela prática de crimes previstos no Estatuto ou por motivações políticas, nos casos em que o Estado estrangeiro for contra a intervenção dessas tropas. Mesmo os EUA não fazendo parte do Estatuto de Roma, isso poderia acontecer com base no artigo 12, que estabelece a competência jurisdicional do Tribunal. ${ }^{22}$

${ }^{21}$ PIOVESAN, Flávia. IKAWA, Daniela Ribeiro. O Tribunal Penal Internacional e o Direito Brasileiro. In: FERRAZ, D.A. HAUSER, D.A. A Nova Ordem Mundial e os Conflitos Armados. Belo Horizonte: Mandamentos, 2002.

${ }^{22}$ Por esse motivo, é grande a pressão para que o maior número de países assinem os BIAs (Bilateral Immunity Agreements). Esses acordos bilaterais pretendem proteger os militares americanos da jurisdição do TPI e, segundo Tatyana Scheila Friedrich, prevêem, inclusive, a suspensão de ajuda militar a Estados que forem partes do TPI e não assinarem o acordo. Esse

Revista Brasileira de Direito Internacional, Curitiba, v.1, n.1, jan./jun.2005 


\section{O CASO DE DARFUR NO SUDÃO}

O fato de o Conselho de Segurança ter competência para denunciar ao Procurador qualquer situação em que haja indícios de ter ocorrido a prática de um ou mais crimes tipificados no Estatuto de Roma fez com que, em 31 de março de 2005, o CS se manifestasse sobre a situação de Darfur, no Sudão, e remetesse o caso ao TPI.

Os diversos conflitos que vêm acontecendo na região, as diversas formas de desrespeito aos direitos humanos e humanitários, a suspeita de genocídio, além da enorme quantidade de refugiados e deslocados internos, chamaram a atenção da comunidade internacional e do Conselho de Segurança da ONU, principal responsável em prevenir e controlar esse tipo de situação.

Assim, após várias reuniões, o CS, em uma decisão histórica, encaminhou pela primeira vez um caso ao TPI, mesmo o Sudão não sendo membro do Tribunal. Após a aceitação do caso pelo Procurador do Tribunal, Luis Moreno-Ocampo, foram iniciadas as investigações das denúncias dos crimes cometidos na região em junho de 2005.

O fato de ter assinado o Estatuto de Roma, mas não ser Estado-Parte do Tribunal não cria nenhuma obrigação do Sudão com o TPI, já que de acordo com as regras de Direito Internacional, os Tratados Internacionais não beneficiam nem prejudicam terceiros. Por esse princípio o Sudão não seria obrigado a entregar seus nacionais ao Tribunal. A exigência de cooperação do Sudão com a Corte, no entanto, resulta do seu comprometimento com a ONU, já que faz parte dessa Organização. Dessa forma, sua colaboração poderá ser exigida pelo Conselho de Segurança e a recusa ao cumprimento de uma determinação desse órgão está sujeita a sanções.

Embora o Brasil manifeste-se a favor do respeito aos Direitos Humanos e tenha se comprometido a cooperar com o Tribunal, absteve-se na votação que ocorreu na ONU para decidir sobre o encaminhamento do caso Sudão ao TPI. A razão dessa posição brasileira deve-se ao fato de a Resolução 1593 do 
Conselho de Segurança ${ }^{23}$, que encaminhou o caso ao Tribunal, fazer restrições quanto ao julgamento de pessoas de outras nacionalidades. $O$ ponto 6 dessa Resolução pode trazer prejuízos à competência do Tribunal e deixar responsáveis por crimes impunes, pois confere imunidade de jurisdição quando decide que:

\footnotetext{
"Los nacionales, los ex funcionarios o funcionarios o el personal de un Estado contribuyente que no sea el Sudán y no sea parte en el Estatuto de Roma de la Corte Penal Internacional se sometan a la jurisdicción exclusiva de ese Estado contribuyente respecto de todos los supuestos actos u omisiones derivados de las operaciones en el Sudán o relacionados con ellas establecidas o autorizadas por el Consejo o la Unión Africana, a menos que esse Estado contribuyente haya renunciado expresamente a dicha jurisdicción exclusiva".
}

Uma vez que a jurisdição sudanesa teve a oportunidade de manifestarse e não o fez, o Tribunal Penal Internacional tem legitimidade para efetuar uma investigação e, se for o caso, julgamento dos responsáveis, baseando-se no principio da complementaridade. No entanto, mais recentemente o governo sudanês estabeleceu o Tribunal de El Fashir para supostamente julgar os responsáveis pelos crimes e impedir a jurisdição internacional. Vários países concordam que o estabelecimento desse tribunal é uma estratégia do governo para evitar a jurisdição do TPI. Por se tratar de um tribunal de exceção frente a uma Corte permanente, ainda há muitas questões a serem estabelecidas para só então se definir se o caso permanece no TPI ou será novamente encaminhado ao Sudão, para que os responsáveis sejam julgados no próprio Estado.

pelo Congo e Uganda, cujas denúncias de crimes já estão sendo investigadas pelo Tribunal. ${ }^{23}$ Resolução 1593 (2005), aprovada pelo Conselho de Segurança em sua $5158^{\circ}$ sessão, celebrada em 31 de março de 2005.

Revista Brasileira de Direito Internacional, Curitiba, v.1, n.1, jan./jun.2005 


\section{CONSIDERAÇÕES FINAIS}

As intromissões do CS no Estatuto, se mal utilizadas, podem causar grandes prejuízos para a jurisdição do Tribunal, uma vez que os membros permanentes do Conselho de Segurança são potências com grande influência internacional.

A revisão do Estatuto, que ocorrerá em 2009 para tentar resolver questões pendentes, como a definição do crime de agressão e possíveis mudanças no tratado, dificilmente conseguirá reduzir a influência do CS no TPI. Embora o Conselho de Segurança não seja membro do Estatuto e, portanto, não possa interferir diretamente nessa revisão, não se pode esquecer de sua força política, capaz de influenciar alguns Estados.

No entanto, a questão da interferência do Conselho de Segurança, um órgão basicamente político, em um Tribunal que se propõem a exercer uma jurisdição imparcial e autônoma, é apenas uma das muitas questões que trazem insegurança aos países signatários do acordo e que ainda devem ser discutidas.

É importante também questionar até que ponto essas questões não prejudicarão o TPI, um tribunal criado para substituir os tribunais ad hoc criados por resoluções do Conselho de Segurança e os tribunais impostos por vencedores, como o Tribunal de Nuremberg. Deve-se impedir que os tribunais de vencedores sejam substituídos por um tribunal de dominadores, no qual os países ditos desenvolvidos e com melhores condições passem a ditar as regras nos julgamentos dos nacionais de países "periféricos", e a história se repita. Dessa forma, o TPI pode tornar-se uma jurisdição apenas para países mais pobres, já que este se baseia no princípio da complementaridade e não tem primazia sobre as jurisdições nacionais, como acontecia nos tribunais ad hoc, e os países desenvolvidos possuem mais recursos para julgar esses casos dentro do próprio Estado, não sendo necessário fazer a entrega dos indivíduos ao Tribunal.

Além disso, o fato de haver apenas casos de países africanos em andamento na Corte não pode impedir que outras violações de direitos 
humanos, provocadas por nacionais de outros continentes, cheguem ao conhecimento da Corte.

Embora seja um grande passo para o Direito Internacional, a criação do TPI está sujeita a diversas críticas originárias principalmente de países que defendem a continuidade de tribunais ad hoc.

Revista Brasileira de Direito Internacional, Curitiba, v.1, n.1, jan./jun.2005 


\section{REFERÊNCIAS}

ARENDT, Hannah. Eichmann em Jerusalém. Um relato sobre a banalidade do mal. Tradução de José Rubens Siqueira. São Paulo: Companhia das Letras, 1999.

CÂMARA DOS DEPUTADOS. O que é o Tribunal Penal Internacional. Brasília: Coordenação de Publicações, 2000.

CHOUKR, Fauzi Hassan. AMBOS, Kai. Tribunal Penal Internacional. São Paulo: Revista dos Tribunais, 2000.

DELGADO, José Manuel A. de Pina e TIUJO, Liriam Kiyimi. Tribunais Penais Internacionais. In: BARRAL, Welber (org.). Tribunais Internacionais: mecanismos contemporâneos de solução de controvérsias. Florianópolis: Fundação Boiteux, 2004.

FRIEDRICH, Tatyana Scheila. O primeiro aniversário do Tribunal Penal Internacional. Disponível em: <www.parana-online.com.br>. Acesso em 05/04/2005.

JARDIM, Tarciso Dal Maso. O Tribunal Penal Internacional e sua importância para os Direitos Humanos. Disponível em:

<www.dhnet.org.br/direitos/sip/tpi/dalmaso.htm>. Acesso em: 07/07/2005

MELLO, Celso D. de Albuquerque. Curso de Direito Internacional Público. 11. ed. Rio de Janeiro: Renovar, 1997.

PIOVESAN, Flávia. IKAWA, Daniela Ribeiro. O Tribunal Penal Internacional e o Direito Brasileiro. In: FERRAZ, D.A. HAUSER, D.A. A Nova Ordem Mundial e os Conflitos Armados. Belo Horizonte: Mandamentos, 2002.

SEITENFUS, Ricardo. Manual das Organizações Internacionais. Porto Alegre: Livraria do Advogado, 1997.

SENNI, Tommaso. II Tribunale Penale Internazionale: il problema del ruolo del Consiglio di sicurezza della Nazioni Unite. Disponível em:

$<w w w$. rivistagiuridica.it/articoli/ig_dot_16042002_01.htm>. Acesso em: 20/12/2005.

SOARES, Guido Fernando Silva. Curso de Direito Internacional Público, v. 1. São Paulo: Atlas, 2002.

VIVANCO, J. C, James. Tribunal de Direitos Humanos: cadê o Brasil? , Disponível em: www.dhnet.org.br/direitos/sip/tpi/james.htm. Acesso em 07/07/2005.

Revista Brasileira de Direito Internacional, Curitiba, v.1, n.1, jan./jun.2005 